\title{
The Impact of Income Inequality on the Economic Growth of Iran: An Empirical Analysis
}

\author{
Elham Jafarzadeh \\ PhD Candidate, School of Economics, Shanghai University, China
}

\section{He Shuquan}

$\mathrm{PhD}$, Professor, School of Economics, Shanghai University, China

\begin{abstract}
In the 20th century, discrimination in the progress rate of people's living standard in different regions of the world remains. The ratio of poverty has been dropped significantly in developing countries during the last two decades, but the improvement has been nevertheless unequal (the annual statistics of the World Bank reports). Since 1981 to 2001, a fall from 1.5 billion to 1.1 billion of a number of people living under poverty has been recorded. Yet many developing and less developed economies are caught in circumstances leading to neverending poverty. For instance, Sub-Saharan Africa has witnessed an increase in poverty with numbers growing from 41 percent to 46 percent in the same time span (1981-2001). At the same time as in Eastern Europe and Central Asia, poverty rose about 20 percent in 2001. For that reason, poverty reduction spread at a large scale is the most demanding target for developing countries with low-income.
\end{abstract}

After reviewing the related literature, it has been witnessed that the available empirical evidence so far does not specify an obvious increase in the worldwide economic inequality. There is a slight uncertainty in the belief that in terms of income per capita the gap among the richest and poorest economies has been amplified. However, this does not essentially mean worsening of income distribution between countries or the world's population. Actually, there is no concurrence among economists so far that income distribution is deteriorated in a large number of economies in the recent past. Therefore, no simple outcome can be derived regarding income distribution trends in general from observing different countries situations. There are a small number of empirical studies that tried to build compound indicators for economic inequality at the global level. However, this does not construct definite evidence of increasing inequality. To sum up, the available empirical literature on trends in the global economic inequality is still insufficient and inconclusive.

This research study considers the role of income inequality, trade openness and GDP per capita in enhancing economic growth of Iran. The dissertation studies the changes in the global economic inequality and its relationship with Iran's economic growth.

Keywords: income inequality, economic growth, Iran.

JEL Classification: D63, E24, F43, O1.

Cite as: Jafarzadeh, E., He, Shuquan (2019). The Impact of Income Inequality on the Economic Growth of Iran: An Empirical Analysis. Business Ethics and Leadership, 3(2), 53-62. http://doi.org/10.21272/bel.3(2).5362.2019.

(C) The Authors, 2019. This article is published with open access at Sumy State University.

\section{Introduction}

\subsection{Scope \& Significance of the Study}

A variety of empirical research is available on the connection between the economic growth and international trade. However, there is a lack of research on the impact of international trade on income inequality. Among which, most of the previous studies that emphasized the correlation between income inequality in trade and economic growth applied Ordinary Least Squares to empirically estimate regression for cross-country growth that possesses omitted variable bias. Further, sample selection has been an obstacle in previous research because of inadequate accessibility to analogous inequality statistics. The main finding of this strand of the literature is that there is a negative coefficient of inequality pointed out that the economies that have a more equitable distribution of income (i.e. the lowest Gini index) have a tendency of higher income levels. 
ISSN (online) - 2520-6311; ISSN (print) - 2520-6761

This research study is an effort to address these issues by applying the technique of fixed effect estimation and comparatively more reliable and identical statistics for cross-country assessment simultaneously, and concurrently using the comparable description of variables in each economy and time. The study is an attempt to investigate the determinants and effects of unequal growth rate at the domestic level but as well at international level in case of Iran. The study encompasses a data sample of economic growth, income inequality and international trade from 2000-2016 for Iran to have an empirical analysis of connection among income inequality, international trade, and economic growth.

It is hard to find a success story of any economy with an adaptation of protectionist's policies and strategies regarding international trade. Trade openness simply means the level to which a transaction can take place between locals and foreigners without any kind of intervention from government authorities, such as, tariffs, non-tariff barriers, inspection delays, local content requirements, etc., which increase the cost of transaction in the international market. In spite of the presence of the constant focus on the extent to promote a trade-led growth, it also proposed theoretical review on the existence of abnormalities, such as lack of credit market, political instability, low infrastructural improvements, etc., which highlights free trade may not be the best for growth in their presence. For example, a high real return to capital in a country with abundant unskilled labor exceeds its comparative advantage.

Even though if trade liberalization carries much speedy growth, it does not essentially mean, it is a useful tool for reduction of income inequality. If a growth policy based on trade liberalization escort to a considerable deterioration of household income inequality, it could not be considered as a measure of poverty reduction. The effect of trade on the distribution of income in a country is simply an empirical issue. This study attempted to identify the relationship among income inequality, international trade, trade policy (trade openness) and GDP per capita in promoting the economic growth of Iran.

\subsection{Literature Review}

Regarding the empirical analysis of the subject, there is a wide range of studies examining international trade and economic growth. Among which some of the prominent studies like, Frankel and Romer (1999) and Sachs and Warner (1995) advocated the growth encouraging effect of international trade. Sachs and Warner study the effect of trade openness on economic growth from data set of 122 countries and found that relatively economies that are more open hold highest growth rates than those economies that observe protectionism. Likewise, Frankel and Romer described that trade liberalization bore rising levels of income in the crosssection analysis of 63 economies in 1985. Similarly, the latest literature also holds the statement that there is a major contribution of trade liberalization in economic development and growth (Dollar and Kraay, 2004; Calderon et al., 2004). It shows that the increase in trade openness (measured by trade volume) carries higher rates of economic growth. The major feature distinguished in the recent research appears to be an analysis of panel data set through the application of the Generalized Method of Moments (GMM) estimator. In such a process, endogenous and omitted fixed variables bias can be handled.

$\mathrm{Fu}$ (2004) investigated the impact of exports on the progression of China's economic development and shows that trade-oriented dynamic gains resulting from trade openness usually occurs in the shape of productivityenhancing gains. It is important to mention that the empirical estimation and the significance of results in the above studies have been faced by criticism (Sachs and Warner, 1995; and Frankel and Romer, 1999). Actually, these articles used "volume of trade", that could probably be associated with geographic characteristics and economic institutions. Roderick et al. (2004) estimated empirically the effect of organizations, geography and trade on income in 1995 for a cross-sectional data set of 140 countries. Subsequent to control the institution's quality, the outcome showed no major impact of trade on economic growth.

The main question arising from the association between openness and growth is that few analysts, like Chang et al. (2009), argue that the effect of trade on growth should not be anticipated identical across different countries. Consequently, trade-led growth effect may be restricted to structural features and economy's primary level of the income. Chang et al. (2009) has done an empirical evaluation of this hypothesis by presenting different interface variables of trade openness regarding inflation, education, governance, and infrastructural development, and so on. Their findings showed a positive effect of trade liberalization just in case of certain circumstances. For example, trade has a positive effect on income per capita just for the well flexible labor market. There is also a profusion of literature that presents evidence regarding the trade led growth conditional upon initial level of income. 
Business Ethics and Leadership, Volume 3, Issue 2, 2019

ISSN (online) - 2520-6311; ISSN (print) - 2520-6761

Noguer and Siscart (2003) reconsidered the association among trade and income and claimed that the estimates remained significant and positive yet after the introduction of geographical controls of Rodriguez and Rodrick. They employed a better quality data set without attribution phase to obtain estimates more accurately. As a result, they have significant findings to a wide range of institutional and geographical controls, over time, and utilized the somewhat different tool. It also depicts that while productivity increases; trade influence income through the improved accumulation of capital.

International trade encourages economic growth by different means through a more efficient allocation of resources. Trade encourages economic growth by enhancing economies of specialization and allows a country to be more productive in fields where they have a comparative cost advantage over other countries. Eventually, this assists economies to create more employment opportunities, and efficient utilization of material and capital resources in sectors where they get maximum gains from open international markets, thus increasing productivity and profits for the workers.

Frankel and Romer (1999), analyzed data on 100 nations from 1960 and concluded that trade openness generally does not have a significant statistical and economic impact on growth. Hiranya and Abdullah (2004) analyzed trade openness, growth and income inequality found in Bangladesh and concluded that to some extent trade openness has a positive effect on economic growth as well as a slight effect on the distribution of income or income distribution impact on the growth and investment. However, the quality of the data on income inequality in the study has poor quality.

The results derived from OLS method showed that open emerging countries practiced increased economic growth at a rate of $5.0 \%$ per capita, rich economies grew by $2.2 \%$ per capita during the 1990s globalization, while developing countries observing protectionism grew at just $1.4 \%$ per capita. Whereas, an increase of hundred percent in the share of trade would have a cumulative impact of increased revenue by twenty-five percent over ten years. Data on income inequality and poverty are extremely dubious. Many emerging economies did not conduct appropriate annual household surveys; therefore, the researchers just have to utilize available data.

\section{Theoretical Framework on Trade, Income Inequality \& Economy Growth of Iran}

\subsection{Linking Iran's Trade Liberalization to Economic Inequality}

The question of the potential link between the international economic inequality and Iran's trade liberalization as well has remained contentious in the economic literature. In this situation, basic economic theory does expect that Iran trade growth would lead to lower income inequalities across trading countries. As well as, it also estimated that under certain conditions, income distribution is worsening in the rich countries, but will improve in poor countries and thus the same case in Iran too. However, these estimations, on the one hand, have been based on some questionable assumptions, while on the other hand, do not properly represent the global economic inequality. Initially, there is no reason to assume that all provinces of Iran must have to grow as successful trading nations when the expansion international occurs. As it is well known, that for instance during the initial phase of globalization, only a few European countries and the "New World" have emerged as significant trading countries. Similarly, it appeared that these countries have shown notable unions between themselves, income -gap among them and the rest of the world expanded quite dramatically. Further, economic theory illustrates that only when there is an expansion of trade, distribution of income get better off in some countries and worsening in others; but does not mention anything about the consequential change in the global distribution of income.

The following section is dedicated to the empirical analysis of global economic inequality trend since the early eighties. It initiates with a look at the different concepts of the lack of global economic inequality used in the present literature. Then it concentrates on the concepts that are referred to as proper measures in perspective of this study and is in accordance with the analysis of trend. The subsequent section attempts to examine the degree of the trends observed in the global economic inequality may have been associated with Iran's global trade trends. It can conclude policy apprehensions.

\subsection{Recent Trends in Iran's Income Inequality \& Economy Growth}

There are three probable means of measuring the economic inequality in Iran. The first procedure refers to inequality between countries in terms of per capita GDP. This provides effective and individual treatment to each country so that the inequality is related to the distribution of per capita GDP between countries. The issue, definitely, is only the GDP per capita of Iran without comparison with other countries. The second instrument 
ISSN (online) - 2520-6311; ISSN (print) - 2520-6761

is that of economic disparity in Iran. This allows weights in form of the size of the population in a country. However, we assume that everyone in a given country would get the same income equivalent to the gross domestic product per capita in this country. The third procedure is that the inequality in the distribution of Iranians total income. Disposable personal income is the related idea of the income here.

In principle, the income distribution in Iran can be acquired through a combination of observations either on income distribution inequality summary indicators in each country or on real income by individual or group (ten or five groups) of the individuals received every country in the globe. Concepts of inequality enshrined in the three measures are obviously very distinct. The prevailing evidence on tendencies in worldwide economic inequality can be derived generally from two kinds of analysis. The first type is interested in statistical and empirical studies checking the convergence or integration hypothesis. This supports the argument that the least developed countries and regions should be anticipated to have rapid development than the most advanced countries. The hypothesis indicates the disparity between countries and suggests that we should be expecting this to fall with the passage of time. Three major opinions have been put forward to hold the hypothesis.

Less developed economies must have to attain high growth rates in order to have the equivalent of the investment. The significant number of workers in the less developed economies inclined to be in the lowproductivity agricultural sector.

With the emerging increase in growth, labors transition switches to highly productive manufacturing and service sectors. Structural modifications in employment along with economic growth are therefore a cause increase the productivity of labor. The main effect of that is, decreases with development as the productivity inclined to the development of different parts, and less number of labor will stay in low productivity part.

However, not a single of these points of view is fully convincing. First, the progress of technological boundaries can be a perception of the kind that there remains a persistent technological gap among the pioneer and the latecomers as well as in case of Iran too. There is no explanation of why the pioneers cannot get benefits from the accumulated practice growing leading-edge techniques. Secondly, as there is a vast opportunity for "learning by doing" there may, in fact, be fixed or even increasing returns to input factor. Thirdly, accurately because of equalizing requirements, there is a propensity (even coercion), in emerging economies, for an untimely implementation of low labor-intensive technologies so that the procedure of labor movement (from less productive to high-productive activities) inclined to be very slow indeed. As a consequence, productivity gains resulting from the operations of labor transfer between sectors usually tend to be quite weak or average.

The economic inequality can be defined at least in three different ways and the outcome about the trend of variation to a great extent relies on the specific description used for analyzing the change. So, in reality, the inequality between the countries is rising, but the global inequality declines alongside. Each of these concepts of inequality does not consider the distribution of income within the country. Research on the evaluation of the international income distribution is in its initial phases, and it is not comprehensible to define whether this distribution has been deteriorating or improving in case of Iran.

There are two other important facts, firstly the growth of inequality between countries signifies a persistence of a long-run trend, and the lower economic inequality indicates a flaw from the precedent. The inequality between the countries has been growing almost since 1950 and more possibly since 1870 . Global inequality has been through the stages of the growth and stability from the late seventies until 1870, depicting a downward tendency for the first time throughout the eighties and nineties. Reduced economic inequality is hence a new characteristic of the global economy. In fact, it is an aspect that differentiates the present phase of globalization from the previous phase (1870-1910), which was connected with the growth of economic inequality.

Secondly, in the early eighties, the economic inequality was much higher than the discrepancy between countries (which means that the most densely populated countries tend to be poor); in fact, it seems that this was a characteristic of the global economy for a relatively long period of time. Divergent tendencies in two of the inequalities in the eighties and nineties escort to their convergence. In the late nineties, it was almost two distinctions from the same system.

\subsection{Empirical Integration between Per Capita GDP and Income Inequality of Iran}

The standard technique for testing the empirical integration hypothesis of determining the association connecting the initial level of Iran's GDP per capita and its growth rate on cross-section data during a specific period. A common result derived from such analysis is that there is little evidence of a trend of integration between Per Capita GDP and Income Inequality of Iran and on a regional basis too, although it is likely to 
determine the integration of some countries that depicts convergence between them, for the certain periods. This means that inequality between countries has no long-run trend to decrease.

Studies have tried to estimate directly the international indicators of inequality for a special time to measure trends. These studies can also be explained as discovering the convergence hypothesis. The main attention, however, is placed on the distributional results for growth instead of focusing on growth processes. The availability of dollar value of GDP estimates in "purchasing power parity" (PPP) for a lot of countries currently makes it comparatively easy to determine global economic inequality and numerous studies tries to analyze the trend in this kind of inequality.

However, GDP per capita is a weak index to determine the social welfare and income distribution within a country and can be uneven to a great extent. If the well-being of the global population is concerned, international inequality then should clearly mean the inequality of the world income distribution. Unluckily, the statistical data available on income distribution in case of Iran, besides being insufficient, also bear severe issues of credibility across countries and over-specification of time. Thus, despite several attempts has been made to predict indicators the distribution of income in case of Iran, and the effectiveness of these estimates it leftover exposed to logical uncertainties.

A number of studies concentrated on the associated concepts of inter-countries and global economic inequities, these analyses did not try to assess the inequality in the distribution of world income. Explanation for this selection of interest is not only result that measured cost of quantitative indicators for the distribution of global income is much more than its advantages (due to the limited statistical data), but as well there is no known technique for study the impact of trade on the distribution of global as well as Iran's income.

Some serious problem about lack of data of income in Iran acutely bound the efficiency of quantitative indicators of economic income distribution and inequality, which can be calculated. Moreover, the period of these points differs from country to country. Thirdly, ideas, descriptions, and methods of sampling, as well as coverage, differ widely across countries. Therefore, any effort to draw Iranian income distribution of data at the country level distribution of income will face serious issues of credibility and also comparative analysis among countries and time. While statistical methods can give a sensible solution to some issues, and there is a need to simplify the assumptions to beat the others especially in case of Iran.

Furthermore, in theory the mechanism, nature, and magnitude of the impact of Iran's trade on the income distribution are not clear. It is convenient to estimate the effect of trade on inequality between countries as far as the impact is observed on economic growth. The connection between trade and inter-country inequality, however, is not easy. It is traceable analytically, to this degree, but there is no theoretical complexity in analyzing the impact of trade on global economic inequality. Variation in the inequality between countries, however, indicates no practical evidence about the changes in the global distribution of income. In fact, even after assuming that the distribution of income in Iran remains unaffected, it is still not possible to estimate the change in income distribution in case of Iran's on the base of observed variations inter-countries inequalities. The reason is that change in global income distribution will still dependent on the impact of relations between the countries' comparative situation as expressions of per capita income, population size, and the degree of inequality at the country level.

Another option is to spotlight the changes in the distribution of income across the country as it is not known that at what intensity it is affected by trade. Unluckily, changes observed in the distribution of personal income in each country as well could not present any evidence of changes in the global distribution of income. Therefore, it is unfeasible to estimate changes in the distribution of world income on the base of interpretation from the changes in the individual countries distribution of income. The deterioration of individual income distribution in one or more countries can actually be in conformity with any deterioration, stability, or enhancement in the global distribution of income.

\section{Empirical Framework Analysis and Methodology}

This study aims to find out the empirical role of international trade and inequality in Iran's economic growth. For that purpose, various techniques have been applied. The results of these techniques and their proper explanation are also briefly explained in this chapter. Moreover, this chapter will clearly show the true picture regarding the role of income inequality and international trade in economic growth of Iran from 2000-2016.

This research study will test the following hypothesis: 
$\mathbf{H}_{\mathbf{0}}$ is the income inequality doesn't have any significant impact on economic growth of Iran. ${ }^{1} \mathbf{H}_{\mathbf{1}}$ is the income inequality has a significant impact on economic growth of Iran.

\subsection{Area of the Study}

The area selected for this study is Iran. The mixed economic system is followed in Iran. Technically Iran is experiencing the transition economy in which approximately sixty percent is running by the central government and remaining forty percent by the private sector. The dominant sector of the Iranian economy is oil and gas production.

The annual GDP growth rate ranges from $4 \%$ to $4.5 \%$ during the last decade. The estimated Nominal GDP during 2015 is 417 billion US\$ and about 1.357 trillion US\$ (estimated by purchasing power parity approach). The current GDP growth rate is $4.3 \%$ and the targeted GDP growth for the year 2016 and 2017 is $4.4 \%$ and $4.9 \%$ respectively.

The GDP per capita of Iran growing year by year that indicates that the standard living of Iranians people is improving as well as the economy of Iran grows. The estimated GDP per capita during 2015 is 4769 US\$ (estimated by IMF) and stands at a range of 96th in world countries. The GDP per capita of Iran on purchasing power parity is US\$ 17400 during 2015 and stands at a rank 71st country in total world countries.

The income inequality in Iran's during 2015 estimated by Gini coefficient is $0.39 \%$. The unemployment rate is high and remains up to $12.2 \%$. The prices rose at a creeping rate and the inflation rate is $7.5 \%$. The poverty rate is $3.1 \%$ (US \$ 2/day) and about $9.1 \%$ people of the total population lives below the poverty line if estimated US \$ 5/day. The total exports of Iran during 2015 are 78.99 US\$ billions and imports were US\$ 70.63 billion.

The contribution of real sectors to Iran's economic growth is satisfactory and improving. During 2015, the contribution of the services sector is relatively high as compared to other sectors. The contribution of the services sector reached fifty percent. The contribution of the manufacturing and industrial sector is $40.9 \%$ and that of the agriculture sector is about $9.9 \%$ to the economic growth of Iran.

The sectoral contribution to Iran's economic growth during 2015 is as follows. The household consumption contributed to an about $45.4 \%$ to growth. The government expenditure is an important element of the economy and it has contributed $14.1 \%$ during 2015 to the Iranian economy. No doubt, the policymakers and economist of any country are interested and focused on the investment for rapid growth. The gross fixed capital investment during 2015 contributes to $31.1 \%$ to Iran's GDP while inventories investment remains $1.2 \%$. The contribution of exports to the whole economic growth of Iran during 2015 was $20.8 \%$ while that of imports was $12.7 \%$.

The major and important economic agreements and trade treaties signed by Iran with other countries include Regional Cooperation for Development (RCD), Economic Cooperation Organization (ECO), World Trade Organization (WTO), Gas Exporting Countries Forum (GECF) and Organization of the Petroleum Exporting Countries (OPEC).

\section{Estimation Technique, Results, and Discussion}

It is very difficult to explain the relationship and impact of trade liberalization, income inequality, and economic growth. Due to the existence of a high gap in the previous literature concerning the cited issue, this study is an empirical one. Thus, it recommends to clearly find and explain the role of trade liberalization and income inequality in the economic growth of Iran for the period of 2000-2016.

\subsection{Economic Growth \& Income Inequality Parameters Estimation}

After reviewing the relevant literature it is evident that the prevailing empirical facts do not clearly indicate the growth of the worldwide economic inequality. There is some ambiguity about the gap among the rich and poor countries in the form of per capita income is expanding; however, this does not essentially mean a worsening of income distribution among countries.

${ }^{1}$ Shows Alternative Hypothesis 
Table 1. Income Inequality \& Economic Growth Parameters Estimation Results

\begin{tabular}{|l|c|c|c|c|}
\hline \multicolumn{1}{|c|}{ Variables } & Co-efficient & Standard Errors & t-statistics & Prob. Value \\
\hline IEQ & -0.132615 & 0.052084 & -2.546137 & 0.0243 \\
\hline GDPPCI & 0.268319 & 0.080289 & 3.341897 & 0.0000 \\
\hline TRP & 0.163807 & 0.086330 & 1.897451 & 0.0673 \\
\hline Pop & 0.253417 & 0.095364 & 2.657341 & 0.0152 \\
\hline Inf & 0.086724 & 0.044327 & 1.956427 & 0.0563 \\
\hline
\end{tabular}

Source: Authors own calculation

In any situation, no simple outcome about the tendency in the distribution of global income is recognizable from the trends observed from a particular country's distribution of income. There are some empirical studies that attempted to build sophisticated indicators for worldwide economic inequality, but this does not provide unequivocal evidence of inequality growth. To be specific, the available empirical evidence so far on trend in the worldwide economic inequality is still inconclusive and insufficient.

The question of the potential link between the international economic inequality and economic growth remained contentious in the economic literature. The results of this study given in above table show that income inequality has an inverse effect on the economic growth of Iran and if income disparities continue to increase it may bring thirteen percent decrease in Iran's economic growth. However, the other explanatory variables that contain Per capita GDP, trade openness policies, population, and inflation having a positive and significant contribution to the economic growth of Iran.

\subsection{Short-run and Long-run Analysis on the Effect of Income Inequality on Iran's Economic Growth}

In the emerging economies, globalization has a negative correlation with the increase in inequality, however, it is not significant in case of developed economies. As a whole for the observed data set, the deterioration of the globalization index is linked with an increase in inequality for all countries under observation.

Table 2. Short-run and Long-run IT, IEQ \& Economic Growth Parameters Estimation Results

\begin{tabular}{|l|c|c|}
\hline \multicolumn{1}{|c|}{ Variables } & Short- Run Co-efficient Results & \multicolumn{2}{c|}{ Long- Run Co-efficient Results } \\
\hline \multirow{2}{*}{ IT } & $0.426425^{*}$ & $0.453672^{*}$ \\
& $(0.241362)$ & $(0.198375)$ \\
\hline \multirow{2}{*}{ IEQ } & $-0.243547^{* *}$ & $-0.162781^{*}$ \\
& $(0.086743)$ & $(0.160958)$ \\
\hline \multirow{2}{*}{ GDPPCI } & $0.635123^{*}$ & $0.573526^{*}$ \\
& $(0.126138)$ & $(0.316020)$ \\
\hline \multirow{2}{*}{ TRP } & $0.123426^{* *}$ & $0.1634251^{* *}$ \\
& $(0.041704)$ & $(0.053082)$ \\
\hline \multirow{2}{*}{ Pop } & $0.476572^{*}$ & $0.578493^{*}$ \\
& $(0.203146)$ & $(0.187473)$ \\
\hline \multirow{2}{*}{ Inf } & $0.103425^{* *}$ & $0.124375^{* *}$ \\
& \multicolumn{3}{|c|}{$(0.037026)$} & $(0.070136)$ \\
\hline
\end{tabular}

Parenthesis shows standard errors. (**) \& (*) show significance at $5 \%$ and $1 \%$.

Source: Authors own calculation

The main concern regarding this trend is the realization that income inequality among countries and peoples has been growing all over the world most prominently in the previous two decades, which has been evident from various well-known case studies. More generally the trend has been realized on a large scale, for instance, the gap in per capita income among the poorest and richest economies has significantly risen over the previous twenty years. Actually, in general, it has been observed that an increase in the growth of per capita income has a much slower propensity in poorer economies. Recent research studies in this regard also suggested a trend of income inequality is growing in a number of economies. Consequently, it is certain to think about the worsening situation of income distribution within states as well as among overall world's population.

It is feasible to conclude that trade liberalization and Income disparities have widened the effect on the growth of the world's economies, especially in developing countries. It is more inclined to high-income countries. From the above results, however, it can be concluded that income inequality raises more in the short-run than in the long-run in case of Iran. In contrast, if the rate of per capita income and growth is high in the long-run then income disparities will be less in Iran. 
ISSN (online) - 2520-6311; ISSN (print) - 2520-6761

There is a slight uncertainty in the belief that in terms of per capita income the gap among the richest and poorest economies has been amplified; however, this does not essentially mean worsening of income distribution between countries or the world's population. Actually, there is no concurrence among economists so far that income distribution is deteriorated in a large number of economies in the recent past. Therefore, no simple outcome can be derived regarding income distribution trends in general from observing different countries situations.

\section{Conclusion and Policy Implications}

\subsection{Conclusion}

It is very controversial to correctly articulate that trade liberalization and income inequalities, as well as disparities, are strongly or weakly associated with each other. Some empirical results suggest that trade liberalization is a cause of the increase in income disparities in developing countries. However, the theoretical literature strongly supports the momentous effect of trade labialization on growth, whereas the empirical examinations have mixed findings in this regard as well. The standard factors Proportion theory states that openness should play a balanced role in poor countries and improve Income inequality in rich countries if the skilled nontechnical relative wage is considered a good representative of income inequality. Nevertheless, this prediction is not systematically proved by the data. While increasing trade openness in several East Asian economies Parallel decline in inequality, Latin American countries have ample evidence after liberalization, their income distribution deteriorated.

The empirical investigation of this study paved comprehensive and important analysis on the role of trade liberalization and income inequality in the economic growth of Iran than before. Most of the earlier studies did not provide a persuasive answer to the link between trade openness, income inequality and economic growth in case of Iran. The reason for mixed results depending on the sample, is the econometric technique that leads to an appropriate conclusion regarding the effect of openness and income disparities and the conclusion is not consistent with basic theoretical analysis. This study clearly indicates that there are a strong link and causal relation between income inequality and trade liberalization that ultimately effect the economic growth of Iran.

It may be possible that the model suffers from a problem of endogeny while estimating the openness and inequality on economic growth. Therefore, in the study we applied Generalized Method of Movement (GMM) to avoid the problem of endogeny as well omitted variable case. The GMM uses the instrumental variables case during the regression analysis that avoids and solves the problem of co-linearity as well as endogeny between explanatory and with dependent variables. Most of the earlier studies applied ordinary least square (OLS) for estimation, but one of the major problems that mostly occurred while estimating the variables through OLS is the problem of biases omitted variables case. If regional, national, or group-specific factors influence growth rates, the explanatory variables will capture the impact of these factors and the estimates do not represent the true impact of the explanatory variables.

For the causal relation and long-run relation between openness, income inequality and economic growth of Iran the Granger Causality and Wald test is applied. The result of both tests shows that there is strong causal between openness, income inequality and Iran's economic growth in the long run.

The increasing integration of economies into a global economy in the course of trade is observed as the main reason for the discriminations in income and growth in various economies. The goal of this study is to set up a causal relationship between foreign trade and the growth of GDP per capita. To attain this objective many trade specifications in empirical estimations of growth are described. The dynamic setting is normally applied to trade to GDP ratio, or "trade openness", that is the degree of exports and imports as a percentage of GDP does not efficiently confine the effect of trade on the growth rate of GDP per capita. Supposing the existence of a causal link among trade and income, variation in trade (size) with the passage of time would always result in variations in income. This dynamic impact is not attributed to "trade openness ratio" because of changes volume of trade i.e., numerator, and the connected changes in GDP i.e., denominator, thus "the proportion of trade openness" can both increase or decrease, or remain constant. Based on these considerations, the diverse trade variable is favored: the volume of imports and exports as a proportion to lagged aggregate GDP. This trade measure passes up probable bias when both the volume of import, export and the total GDP change at one time.

The impact of trade liberalization on economic growth in the countries has been a complicated phenomenon. Global trade growth mainly reflects the growth in trade in manufacture. Basically, this is what clarifies the "global exclude" or "marginalization" of a huge segment of the developing countries that were not in a position 
to manufacture for export as they also had no a large manufacturing sector and the required material and social infrastructure. They continue to rely on exports of primary commodities, global demand for which was suffering from the recession. In these circumstances, trade liberalization tend to have a confined role and do not have a stimulating effect on economic growth. It has failed to earn high revenues from exports of primary goods but revealed the fledgling industries to international competition.

Developments in global trade, thus concurrently contributed to the growth of the inequality between the countries and to the decrease in global economic inequality. In terms of inter-country inequality, trade liberalization resists to the negative impact of demographic variation. In this situation of global economic disparity, the positive impact of trade liberalization is strong enough to compensate the disadvantageous impact of changing the growth.

Utilizing an alternative measure of trade in arrangement with suitable measures of GMM estimator system permits construction of a causal relationship between trade and GDP per capita growth rate. International trade definitely has a constructive role in the promotion of economic growth rates. It has been demonstrated at large scale that trade expansion and liberalization promotes technological advancements through transactions of commodities embodied with new technologies, and therefore has a considerable effect on income growth as well as on living standards of the people. Additionally, it can be observed that trade and trade expansion both have an independent effect on GDP per capita growth; similar is the case with exports and imports separately.

The confirmation of the positive impact of trade on income growth is also proved from a sample of developing economies only. Trade has been known to be useful determinant in promoting economic growth in developing economies. These results are essential for the present dialogues in "Development Community", as they reinforce the significance of development aid based on trade, for instance, the Aid for Trade.

\subsection{Policy Implications}

This study on the basis of empirical finding has suggested the following policy implication in order to raise the economic growth of Iran via international trade and control and minimized income inequalities and income disparities in Iran.

1. In theory and practice, the fiscal policy has an important effect on economic activities. The impact of the tax is negligible on income inequality while it has a negative impact on international trade. Both the government officials and policymakers have to keep keen interest while proposing and implementing the fiscal policy.

2. The factor endowments and factor proportion play a keen role in growth via international trade as well as in reducing poverty and income disparities. The economist and government officials of Iran need to keep special attention on factor endowments and factor proportion while making fiscal and monetary policy.

3. It has also been observed that the available data regarding the income inequality is neither valid nor ethnic. The government bodies need to provide and collect ethnic and reliable data on income disparities and income inequalities to properly tackle this problem.

4. Interesting questions from the policy Perspectives are that either the countries with different degrees of openness behave differently with income Inequality. To control income inequalities and at the same time to increase the international trade, the policy makers and government bodies need to give equal attention to both at the same time.

5. Whether an increase in a country's trade openness is associated with an increase or a decrease in inequality, both the theoretical and empirical results have mixed finding for it. In case of Iran trade openness and income disparities are strongly correlated with each other.

6. This study also suggesting from its empirical findings that fiscal policy has played a major role in income inequalities. If the government of Iran is really interested in controlling and minimizing the income inequalities and income disparities in Iran, it should be more spot lightening on the fiscal policy.

7. Trade liberalization may affect the factor endowments via exports and productivity that may lead to a significant decrease in income disparities.

\section{References}

1. Acemoglu, D. and David, A. (2011). Skills, Tasks and Technologies: Implicati Employment and Earnings. Handbook of Labor Economics, 4(B), 1043-1171. 
Business Ethics and Leadership, Volume 3, Issue 2, 2019

ISSN (online) - 2520-6311; ISSN (print) - 2520-6761

2. Aghion and Bolton, P. (1997). Distribution and Economic growth in model of imperfect capital Markets. European Economic Review, 36, 603-611.

3. Aghion, P., Caroli, E., and Garsia-Penalosa, C. (1998). Inequality and economic Growth. Cambridge University Press.

4. Ajit, K. G. (2001). Global inequality and international trade. Cambridge Journal of Economics, 28, 229-252.

5. Calderon, C., and Chong, A. (2001). External sector and income inequality in interdependent economies using a dynamic panel data approach. Economic Letters, 71(2), 225-231.

6. Caliendo, L., and Rossi-Hansberg, E. (2012). The Impact of Trade on Organization and Productivity. Quarterly Journal of Economics, 127, 1393-1467.

7. Central Bank of Iran (2007) and (2015). Custom Statistical Yearbook. Available at: http//www.cbi.ir.

8. Chakrabarti, A. (2000). Does trade cause inequality. Journal of Economic Development, 25(2), 324-338.

9. Deininger, K., and Squire, L. (1996). A New Data Set Measuring Income Inequality. The World Bank Economic Review, 10(3), 565-91.

10.Dimitri, P. (2006). Government Effects on the Distribution of Income, an Overview. Working Paper, No. 442.

11.Dollar, D. (1992). Outward-Oriented Developing Economies Really Do Grow More Rapidly: Evidence from 95 LDCs 1976-1985. Economic Development and Cultural Change, 40(3), 523-44.

12.Dollar, D., and Kraay, A. (2000). Growth is good for the Poor. World Bank Policy Research Working Paper, No: 2587, Washington, DC: World Bank.

13.Forbes, K. (2000). A Reassessment of the Relationship between Inequality and Growth. American Economic Review, 90, 869-97.

14.Frankel, J., and Romer, D. (1999). Does trade cause growth? American Economic Review, 89(3), 379-399.

15.Galor, O. (2000). Income Distribution and thePprocess of Development. European Economic Review, 44, 706-12.

16.Galor, O., and Hansen, M. (1999). From Physical to Human Capital Accumulation: Inequality in the Process of Development. CEPR discussion paper, No: 2307.

17.Galor, O., and Weil, T. (1999). From Malthusian Stagnation to Modern Growth. American Economic Review, 89, 150-154.

18.Hiranya, K. N. and Khawaja, A. (2004). Trade Liberalization, Growth and Inequality in Bangladesh: An Empirical Analysis, 13, 1-12.

19.Irwin, D. A., and Tervio, M. (2002). Does trade raise income? Evidence from twentieth century. Journal of International Economics, 58(1), 1-18.

20.Kaasa, A. (2003). Factors Influencing Income Inequality in Transition Economics. University of Tartu, Faculty of Economics and Business Administration, No. 207.

21.Kahai, S. K., and Walter, S. (2005). The Impact of Globalization on Income Inequality. Global Business and Economics Review, 7(1), 1-15.

22.Rodriguez, F., and Rodrik, D. (2001). Trade policy and economic growth: A skeptic's guide to crossnational evidence, in: Bernanke, B.S., Rogoff, K. (EDS), NBER Macroeconomics Annual 2000. MIT Press, Cambridge, pp. 261-325.

23.Romer, C. D., and Romer, D. H. (1998). Monetary Policy and the Well-Being of the Poor. NBER, Working Paper, No. 6793.

24.Ron, D. (2000). Globalization and income inequality: An international perspective. The fifth annual conference on international trade education and research.

25.Ruth-Aida, N. (2005). Income Inequality and Growth: A Panel Study of Swedish Countries 1960-2000. Institute for Future Studies, Working Paper No. 2005: 08.

26.Sachs, J. D. and Warner, A. M. (1995). Economic Reform and the Process of Global Integration. Brookings Papers on Economic Activity, 1-95.

27. Brueckner, M. and Laderman, D. (2015). Effects of Income Inequality on Aggregate Output. World Bank Policy Disccussion Paper 7317.9

28.Brueckner, M., Dabla Norris, E., Gradstein, M. (2015). National Income and its Distributiotion. Journal of Economic Growth, 20, 149-179. 